Ciência Florestal, Santa Maria, v. 23, n. 2, p. 309-320, abr.-jun., 2013

ISSN 0103-9954

\title{
CRESCIMENTO E SOBREVIVÊNCIA DE MUDAS DE SABIÁ (Mimosa caesalpiniaefolia Benth.) INOCULADAS COM MICRO-ORGANISMOS SIMBIONTES EM CONDIÇÕES DE CAMPO
}

\author{
SEEDLINGS GROWTH AND SURVIVAL OF SABIA (Mimosa caesalpiniaefolia Benth.) \\ INOCULATED WITH SYMBIOTIC MICROORGANISMS IN FIELD CONDITIONS
}

\section{Marília Malta Cavalcante Mendes ${ }^{1}$ Lúcia de Fátima de Carvalho Chaves ${ }^{2}$ Tarcísio Pio Pontes Neto ${ }^{3}$ José Antônio Aleixo da Silva ${ }^{4}$ Márcia do Vale Barreto Figueiredo ${ }^{5}$}

\section{RESUMO}

A Sabiá (Mimosa caesalpiniaefolia Benth.) possui a característica ecológica de se associar simbioticamente a bactérias fixadoras de Nitrogênio e fungos micorrízicos arbusculares. Tais associações são utilizadas como ferramentas biológicas capazes de minimizar o uso de fertilizantes químicos e beneficiar o desenvolvimento da planta em ambientes com déficit nutricional. Este trabalho teve como objetivo avaliar o crescimento da Sabiá em resposta à inoculação com rizóbio e fungos micorrízicos arbusculares, estabelecer curvas de crescimento em altura e diâmetro do colo, determinar os conteúdos de $\mathrm{N}$ e $\mathrm{P}$ na parte aérea das plantas e avaliar a sobrevivência das plantas em campo. A estirpe de rizóbio utilizada foi a BR3405, os fungos micorrízicos arbusculares utilizados foram Glomus clarum e Gigaspora margarita. A inoculação conjunta de Glomus clarum + Gigaspora margarita + BR3405 e a inoculação com o isolado Gigaspora margarita promoveram os melhores valores para as variáveis estudadas (altura, diâmetro do colo, conteúdo de $\mathrm{N}$ e P), sendo este último o tratamento mais indicado para o cultivo da Sabiá nas condições em estudo. As plantas apresentaram $100 \%$ de sobrevivência, independente do tratamento utilizado. Não foi constatada diferença estatística para os conteúdos de $\mathrm{N}$ e P na parte aérea da Sabiá, porém, foi observado maior crescimento das plantas com o uso dos simbiontes.

Palavras-chave: leguminosa; fertilidade; simbiose.

\section{ABSTRACT}

Sabia (Mimosa caesalpiniaefolia Benth.) has ecological characteristics and symbiotic associations with nitrogen fixing bacteria and arbuscular mycorrhizal fungi. These associations are used as biological tool that could be used as an able alternative to minimize chemical fertilizer use and benefit plant development at environments under nutritional deficit. The objective of this study was to evaluate the growth of Leguminosae Sabia (Mimosa caesalpiniaefolia Benth.) like response to rhizobia and arbuscular mycorrhizal fungi inoculation, to establish growth curves to height and stem based diameter, to determine the $\mathrm{N}$ and $\mathrm{F}$ contents in plants aerial parts and to evaluate plants survival at field. The strain used was BR3405, The arbuscular mycorrhizal fungi used was Glomus clarum and Gigaspora margarita. The Glomus clarum + Gigaspora margarita + BR3405 and Gigaspora margarita inoculation provided better values for the studied variables (height, diameter, N and P), and this last one was the best choice to Sabia plantation. The plants showed $100 \%$ survival, regardless the treatment ued. There was not significant statistical difference for $\mathrm{N}$ and $\mathrm{F}$

1. Engenheira Florestal, MSc., Instituto Agronômico de Pernambuco, Av. General San Martin, 1371, Bongi, CEP 50761-000, Recife (PE). Bolsista CNPq. mariliamcmp@hotmail.com

2. Engenheira Florestal, Dra., Professora do Departamento de Ciências Florestais, Universidade Federal Rural de Pernambuco, Rua Dom Manoel de Medeiros, s/n, Dois Irmãos, CEP 52171-900, Recife (PE). 1.chaves@dcfl.ufrpe.br

3. Engenheiro Florestal, Secretaria de Agricultura e Reforma Agrária de Pernambuco, Av. Caxangá, 2200, Cordeiro, CEP 50711-000, Recife (PE). tarcisio.pontes@sara.pe.gov.br

4. Engenheiro Agrônomo, Dr., Professor do Departamento de Ciências Florestais, Universidade Federal Rural de Pernambuco, Rua Dom Manoel de Medeiros, s/n, Dois Irmãos, CEP 52171-900, Recife (PE). jaaleixo@uol.com.br

5. Bióloga, Dra., Instituto Agronômico de Pernambuco/SEAGRI, Av. General San Martin, 1371, Bongi, CEP 50761000, Recife (PE). marcia.figueiredo@ipa.br

Recebido para publicação em 25/05/2010 e aceito em 2/12/2011 
content in Sabia aerial part., Nevertheless, it was noticed a faster growth in plants with symbiont.

Keywords: leguminosae; fertility; symbiosis.

\section{INTRODUÇÃO}

A espécie Mimosa caesalpiniaefolia Benth., pertencente à família Leguminosae, subfamília Mimosoideae (LORENZI, 2002), conhecida como Sabiá ou sansão-do-sampo, ocorre naturalmente na região Nordeste do Brasil, em áreas da caatinga do Piauí, Pernambuco, Alagoas, Rio Grande do Norte, Paraíba, Bahia e Ceará (FIGUEIRÔA et al., 2005). Os cultivos dessa espécie possuem diversas finalidades, sendo conhecida como árvore de uso múltiplo e é comumente utilizada para produção de lenha, estacas e carvão. É uma espécie heliófita, de rápido crescimento, fácil renovação pela rebrotação de tocos e raízes, resistente à seca (RIZZINI, 1978), além de ser forrageira (LIMA et al., 2008).

Fornece elevada quantidade de biomassa com significativo aporte de material formador de serrapilheira, sendo importante fonte de nutrientes e matéria orgânica ao solo (SOUZA e SILVA, 1996), podendo proporcionar melhoria na sua estrutura, e servir como cobertura vegetal (SILVA et al., 2009). De acordo com Braga (1976), a espécie é considerada indispensável em qualquer programa de reflorestamento na Região Nordeste do Brasil, pois sendo uma planta nativa, encontra-se mais adaptada às condições ecológicas da região.

Em solos degradados, a perda da matéria orgânica ocasiona problemas na estrutura, disponibilidade de água e atividade biológica, prejudicando o fornecimento de elementos essenciais às plantas, como o P e N (FRANCO et al., 1995). Os micro-organismos exercem papel fundamental na manutenção dos solos, pois estão relacionados a processos-chave que mantêm a estrutura e a fertilidade, como sua participação na decomposição da matéria orgânica (PEIXOTO e ROSADO, 2008).

$\mathrm{O}$ uso de leguminosas associadas a bactérias fixadoras de nitrogênio pode representar uma opção à fertilização química (SANTOS et al., 2008), sendo uma alternativa para alcançar a autossuficiência em nitrogênio (LASTE et al., 2008), e apresentando ainda as vantagens de redução de custos, além de prover equilíbrio ambiental (TOLEDO et al., 2009). De acordo com Araújo Filho et al. (2007), é uma tecnologia viável para recuperação de solos degradados, pois, favorece a sua melhoria, por meio do aporte de matéria orgânica e pela adição e reciclagem de nutrientes. Segundo Ribaski et al. (2003), a Sabiá possui a capacidade de associação simbiótica com bactérias genericamente conhecidas como rizóbio, que fixam o $\mathrm{N}$ atmosférico.

Outra associação benéfica à Sabiá forma-se com os Fungos Micorrízicos Arbusculares (FMA). As hifas do fungo capturam diversos nutrientes minerais, os quais são utilizados pelas plantas nos seus processos fisiológicos (STÜRMER et al., 2009). Em solos de média a baixa fertilidade, os FMA maximizam a eficiência da absorção, principalmente dos nutrientes de baixa mobilidade no solo como $\mathrm{P}, \mathrm{Zn}$ e $\mathrm{Cu}$, tornando-os mais disponíveis às plantas (MIRANDA et al., 2008). Ecologicamente, essa associação proporciona melhor utilização e conservação dos nutrientes disponíveis no sistema solo-planta, por permitir às plantas melhor adaptação ao ecossistema. Os principais benefícios dessa relação para as plantas são alterações metabólicas diversas, que surgem e se refletem positivamente sobre o desenvolvimento e nutrição da planta (COLOZZIFILHO e NOGUEIRA, 2007). Assim sendo, as características das plantas, quando associadas simultaneamente a rizóbio e a FMA, permitem o seu cultivo em áreas degradadas, com maiores chances de se ajustarem às condições edáficas adversas (RODRIGUES et al., 2006).

Este trabalho teve, portanto, o objetivo de avaliar o crescimento da Sabiá em resposta à inoculação com rizóbio e fungos micorrízicos arbusculares, estabelecer curvas de crescimento em altura e diâmetro do colo, determinar os conteúdos de $\mathrm{N}$ e $\mathrm{P}$ na parte aérea e avaliar a sobrevivência das plantas em campo, sob efeito de diferente micro-organismos.

\section{MATERIAL E MÉTODOS}

As sementes de Sabiá (Mimosa caesalpiniaefolia Benth.) foram adquiridas do setor de sementes do Instituto de Pesquisa e Estudos Florestais (IPEF). As mesmas foram submetidas a um processo de quebra de dormência que con- 
sistiu na imersão por 1 segundo, em água a temperatura de $80{ }^{\circ} \mathrm{C}$. Sendo essa operação repetida por trinta vezes, e em seguida desinfestadas por imersão em álcool a $70 \%$, por um minuto, e por três minutos em hipoclorito de sódio a $1 \%$, sendo em seguida lavadas com água destilada autoclavada de acordo com a metodologia de Andrade e Hamakawa, (1994).

Utilizou-se como inoculantes dois isolados de fungos micorrízicos arbusculares (FMA) e um de rizóbio. Os FMA utilizados foram Glomus clarum Nicol. \& Schenck e Gigaspora margarita Becker \& Hall. provenientes do Centro Nacional de Pesquisa em Agrobiologia (CNPAB). Foi feita a contagem do número de esporos pela técnica da decantação e peneiramento úmido (GERDEMANN e NICOLSON, 1963), e complementado pela técnica da centrifugação e flutuação em sacarose (JENKINS, 1964). Para inoculação com os FMA, utilizou-se 1,0 g do inóculo em forma de propágulo por muda, contendo cerca de 180 esporos, por ocasião da semeadura, depositado em íntimo contato com a semente. A estirpe de rizóbio utilizada foi a BR3405, proveniente do CNPAB, bactéria recomendada pela Rede de Laboratórios para Recomendação, Padronização e Difusão de Tecnologia de Inoculantes Microbianos de Interesse Agrícola (RELARE).

A estirpe foi cultivada em meio agar, manitol e extrato de levedura (YEMA) (VINCENT, 1970), purificada no meio YEMA, utilizando-se como indicador o Vermelho-Congo e multiplicada em meio manitol - extrato de levedura (YEM), em agitador rotativo, a temperatura de $28^{\circ} \mathrm{C}$ por um período de três dias, em agitação de $200 \mathrm{rpm}$. A inoculação das sementes com rizóbio foi realizada por ocasião da semeadura, utilizando-se como veículo, turfa neutralizada e autoclavada a $120^{\circ} \mathrm{C}$ sob pressão de $101 \mathrm{kPa}$.

As mudas, num total de 960 , sendo 120 por tratamento, foram produzidas e cultivadas até os noventa dias, em casa de vegetação, em sacos de polietileno com capacidade de $1,5 \mathrm{Kg}$ de solo, contendo uma semente por saco de muda, utilizando como substrato, solo proveniente do campo da Estação Experimental do Instituto Agronômico de Pernambuco (IPA) de Itapirema (Goiana-PE), apresentando as seguintes características químicas $\mathrm{pH}$ em água $=6,4 ; \mathrm{P}=1 \mathrm{mg} \cdot \mathrm{dm}^{-3} ; \mathrm{Na}^{+}=$ $0,02 \mathrm{cmol} \cdot \mathrm{dm}^{-3} ; \mathrm{K}^{+}=0,09 \mathrm{cmol} \cdot \mathrm{dm}^{-3} ; \mathrm{Ca}^{+2}+$ $\mathrm{Mg}^{+2}=2,00 \mathrm{cmol} \cdot \mathrm{dm}^{-3} ; \mathrm{Ca}^{+2}=1,25 \mathrm{cmol}_{\mathrm{c}} \cdot \mathrm{dm}^{-3}$; $\mathrm{Al}^{+3}=0,00 \mathrm{cmol}_{\mathrm{c}} \cdot \mathrm{dm}^{-3}$.
Noventa dias após a semeadura, quando as mudas apresentavam altura média de $50 \mathrm{~cm}$, foram estabelecidas no campo, sem que houvesse nenhuma adubação ou correção do solo, utilizando-se o espaçamento $1 \times 1 \mathrm{~m}$ entre plantas e $2 \mathrm{~m}$ entre parcelas. O local selecionado para o plantio foi uma área de capoeira na Estação Experimental do IPA, em Caruaru, Agreste do Estado que, de acordo com Encarnação (s.d.), possui latitude $08^{\circ} 14^{\prime} 18^{\prime}$ 'S, longitude $35^{\circ} 55^{\prime} 20^{\prime \prime} \mathrm{W}$ Gr., altitude $537 \mathrm{~m}$. O solo da área de plantio apresentava as seguintes características químicas: $\mathrm{pH}$ em água $=$ 6,16; P = 3,0 mg. $\mathrm{dm}^{-3} ; \mathrm{Na}^{+}=0,03 \mathrm{cmol} \cdot \mathrm{dm}^{-3} ; \mathrm{K}^{+}$ $=0,19 \mathrm{cmol}_{\mathrm{c}} \cdot \mathrm{dm}^{-3} ; \mathrm{Ca}^{+2}+\mathrm{Mg}^{+2}=2,40 \mathrm{cmol}_{\mathrm{c}} \cdot \mathrm{dm}^{-3}$; $\mathrm{Ca}^{+2}=1,35 \mathrm{cmol} \cdot \mathrm{dm}^{-3} ; \mathrm{Al}^{+3}=0,10 \mathrm{cmol} \cdot \mathrm{dm}^{-3}$.

Os tratamentos utilizados foram: $\mathrm{T}_{1}=$ Testemunha Absoluta; $\mathrm{T}_{2}=\mathrm{FMA}_{1}=$ Gigaspora margarita $; \mathrm{T}_{3}=$ FMA $_{2}=$ Glomus clarum; $\mathrm{T}_{4}$ $=$ Rizóbio $=$ BR3405; $\mathrm{T}_{5}=$ Rizóbio + FMA $_{1}=$ BR3405 + Gigaspora margarita; $\mathrm{T}_{6}=$ Rizóbio + $\mathrm{FMA}_{2}=\mathrm{BR} 3405+$ Glomus clarum $; \mathrm{T}_{7}=\mathrm{FMA}_{1}+$ $\mathrm{FMA}_{2}=$ Glomus clarum + Gigaspora margarita ; $\mathrm{T}_{8}=\mathrm{FMA}_{1}+\mathrm{FMA}_{2}+$ Rizóbio $=$ Glomus clarum + Gigaspora margarita + BR3405.

Para análise dos dados em altura e diâmetro do colo, o delineamento experimental utilizado foi o multivariado de medidas repetidas, com oito tratamentos e quatro repetições (com área de $25 \mathrm{~m}^{2}$ cada), sendo utilizadas 25 plantas por parcela, totalizando 800 plantas em campo, e sendo consideradas úteis, para fins de avaliações, as nove plantas centrais de cada parcela, de modo a eliminar o efeito de borda. As medidas foram realizadas mensalmente por um período de nove meses. As análises dos dados foram realizadas por meio do software Statistical Analysis System (SAS) e as médias dos tratamentos comparadas pelo teste de Tukey a $5 \%$ de probabilidade.

Aos 150 e aos 240 dias, foi coletado um ramo na altura mediana de cada planta da área útil de cada parcela, para análise e determinação dos conteúdos de Nitrogênio $(\mathrm{N})$ e Fósforo $(\mathrm{P})$. $\mathrm{O}$ delineamento experimental utilizado foi o inteiramente casualizado e as análises dos dados foram realizadas por meio do software Assistência Estatística (ASSISTAT), sendo as médias dos tratamentos comparadas pelo teste de Tukey a $5 \%$ de probabilidade.

Para a modelagem de crescimento das plantas de Sabiá, em altura e diâmetro do colo, na análise dos dados coletados, foi aplicado o teste de Scott-Knott a $5 \%$ de probabilidade para separação 
de grupos estatisticamente semelhantes, por meio do software ASSISTAT. Posteriormente, utilizando-se o software SYSTAT, foi aplicado o modelo de crescimento de Chapman-Richards:

$$
\begin{aligned}
& \mathrm{H}_{\mathrm{f}}=\mathrm{H}_{\mathrm{i}} *\left(\frac{1-\mathrm{e}^{-\mathrm{K}^{*} \mathrm{ff}}}{1-\mathrm{e}^{-\mathrm{K}^{*} \mathrm{i}}}\right)^{\theta} * \epsilon_{\mathrm{i}} \\
& \mathrm{D}_{\mathrm{f}}=\mathrm{D}_{\mathrm{i}} *\left(\frac{1-\mathrm{e}^{-\mathrm{K}^{*} \mathrm{f}} \mathrm{f}}{\left.1-\mathrm{e}^{-\mathrm{K}^{*} \mathrm{t}}\right)^{\theta} * \epsilon_{\mathrm{i}}}\right.
\end{aligned}
$$

Em que: $\mathrm{H}_{\mathrm{f}}=$ altura final estimada; $\mathrm{H}_{\mathrm{i}}=$ altura inicial observada; $\theta$ e $\mathrm{K}=$ constantes; $\mathrm{t}_{\mathrm{i}}=$ tempo inicial das medições das alturas do experimento; $t_{\mathrm{f}}=$ tempo final das medições das alturas do experimento; $\epsilon_{\mathrm{i}}=$ erro aleatório; $\mathrm{D}_{\mathrm{f}}=$ diâmetro final estimado; $\mathrm{D}_{\mathrm{i}}=$ diâmetro inicial observado; $\theta$ e $\mathrm{K}=$ constantes; $\mathrm{t}_{\mathrm{i}}=$ tempo inicial das medições dos diâmetros do experimento; $t_{\mathrm{f}}=$ tempo final das medições dos diâmetros do experimento; $\epsilon_{\mathrm{i}}=$ erro aleatório.

\section{RESULTADOS E DISCUSSÃO}

\section{Crescimento em altura}

Analisando-se, ao longo do tempo, a resposta das plantas de Sabiá aos diferentes tratamen- tos aplicados, até os nove meses de cultivo (Tabela 1), observou-se que, de um modo geral, o melhor crescimento em altura foi obtido pela inoculação conjunta de Glomus clarum + Gigaspora margari$t a+$ BR3405, pois, apesar de não ter diferido estatisticamente de outros tratamentos aplicados, essas plantas obtiveram os maiores valores de altura observados.

Pode-se inferir, portanto, que o melhor desempenho das plantas de Sabiá, obtido pela combinação de FMA (Glomus clarum + Gigaspora margarita) + Rizóbio (BR3405), deve-se ao suprimento adequado de nutrientes necessário para a estabilização da simbiose, uma vez que o adequado fornecimento de P proporcionado pelo FMA favorece o processo da fixação biológica de Nitrogênio (JESUS et al., 2005). Esse balanço adequado de nutrientes favorece a simbiose e se reflete na planta em forma de maior crescimento.

As plantas isentas de inoculações tiveram crescimento reduzido em relação às demais com o passar do tempo. Possivelmente, esse fato pode ser associado com a resposta das plantas, dos demais tratamentos, à colonização pelos simbiontes inoculados.

As plantas inoculadas isoladamente com rizóbio (BR3405) apresentaram um maior desenvolvimento somente a partir dos 90 dias de cultivo, provavelmente, devido ao tempo necessário para o

TABELA 1: Altura média de mudas de Mimosa caesalpiniaefolia Benth., aos 30, 60, 90 dias (em casa de vegetação), 120, 150, 180, 210, 240 e 270 dias (em campo) inoculadas com fungos micorrízicos arbusculares e bactéria fixadora de nitrogênio, no Instituto Agronômico de Pernambuco - IPA.

TABLE 1: Mimosa caesalpiniaefolia Benth. seedlings sward height at 30, 60, 90 days (greenhouse) 120, 150, 180, 210, 240 and 270 days (field) inoculated with arbuscular mycorrhizal fungi and

\begin{tabular}{|c|c|c|c|c|c|c|c|c|c|}
\hline \multirow{3}{*}{$\begin{array}{l}\text { Trata- } \\
\text { mento }\end{array}$} & \multicolumn{9}{|c|}{ Altura $(\mathrm{cm})$} \\
\hline & \multicolumn{9}{|c|}{------Casa de vegetação-------- } \\
\hline & 30 dias & 60 dias & 90 dias & 120 dias & 150 dias & 180 dias & 210 dias & 240 dias & 270 dias \\
\hline $\mathrm{T}_{1}$ & $19,65 \mathrm{abc}$ & $43,36 a b$ & $52,58 \mathrm{ab}$ & $54,76 \mathrm{ab}$ & $56,01 \mathrm{ab}$ & $56,88 \mathrm{abc}$ & $60,47 b$ & $61,47 b$ & $63,90 \mathrm{c}$ \\
\hline $\mathrm{T}_{2}$ & $17,84 d$ & $41,18 \mathrm{bc}$ & $50,62 \mathrm{bc}$ & $51,65 \mathrm{bc}$ & $55,94 \mathrm{ab}$ & $61,68 \mathrm{ab}$ & $73,48 \mathrm{a}$ & $75,76 \mathrm{a}$ & $80,50 \mathrm{ab}$ \\
\hline $\mathrm{T}_{3}$ & $18,34 \mathrm{~cd}$ & $42,04 b c$ & $49,76 b c$ & $51,40 \mathrm{bc}$ & $52,84 \mathrm{~b}$ & $55,33 \mathrm{bc}$ & $64,68 \mathrm{ab}$ & $67,54 \mathrm{ab}$ & $70,73 a b c$ \\
\hline $\mathrm{T}_{4}$ & $18,47 \mathrm{~cd}$ & $40,68 b c$ & $51,68 \mathrm{abc}$ & $53,05 \mathrm{abc}$ & $56,12 \mathrm{ab}$ & $60,62 \mathrm{abc}$ & $69,33 \mathrm{ab}$ & $72,11 \mathrm{ab}$ & $75,91 \mathrm{abc}$ \\
\hline $\mathrm{T}_{5}^{4}$ & $19,40 \mathrm{bcd}$ & $39,48 \mathrm{c}$ & $47,34 \mathrm{c}$ & $49,72 \mathrm{c}$ & $51,73 b$ & $54,19 \mathrm{c}$ & $61,55 b$ & $64,94 \mathrm{ab}$ & $71,45 \mathrm{abc}$ \\
\hline $\mathrm{T}_{6}^{3}$ & $20,66 a b$ & $42,62 \mathrm{abc}$ & $50,84 b c$ & $52,84 \mathrm{bc}$ & $54,40 \mathrm{~b}$ & $56,79 \mathrm{bc}$ & $62,84 \mathrm{ab}$ & $64,23 \mathrm{ab}$ & $68,56 \mathrm{bc}$ \\
\hline $\mathrm{T}_{7}^{0}$ & $19,70 \mathrm{abc}$ & $42,55 \mathrm{abc}$ & $53,76 \mathrm{ab}$ & $55,34 \mathrm{ab}$ & $56,04 \mathrm{ab}$ & $56,95 \mathrm{abc}$ & $60,65 b$ & $61,18 b$ & $63,33 \mathrm{c}$ \\
\hline $\mathrm{T}_{8}$ & $21,36 \mathrm{a}$ & $45,79 \mathrm{a}$ & $56,05 \mathrm{a}$ & $57,98 \mathrm{a}$ & $60,00 \mathrm{a}$ & $63,51 \mathrm{a}$ & $71,58 \mathrm{ab}$ & $75,30 \mathrm{a}$ & $83,55 \mathrm{a}$ \\
\hline CV $(\%)$ & 12,52 & 11,71 & 13,27 & 12,93 & 13,54 & 15,83 & 24,10 & 27,35 & 28,57 \\
\hline
\end{tabular}
nitrogen-fixing bacteria, at Instituto Agronômico de Pernambuco - IPA.

Em que: $\mathrm{T}_{1}=$ Testemunha Absoluta; $\mathrm{T}_{2}=$ Gigaspora margarita $; \mathrm{T}_{3}=$ Glomus clarum; $\mathrm{T}_{4}=\mathrm{BR} 3405 ; \mathrm{T}_{5}=\mathrm{BR} 3405+$ Gigaspora margarita; $\mathrm{T}_{6}=\mathrm{BR} 3405+$ Glomus clarum $; \mathrm{T}_{7}=$ Glomus clarum + Gigaspora margarita $; \mathrm{T}_{8}=$ Glomus clarum + Gigaspora margarita + BR3405. Médias seguidas de mesma letra não diferem estatisticamente entre si pelo teste de Tukey $(\mathrm{P}<0,05)$. 
estabelecimento da simbiose. De acordo com Goi et al. (1992) e Jacob-Neto et al. (1998), citados por Nobre (2008), algumas leguminosas arbóreas necessitam de 20 a 30 dias para exibir indícios de nódulos radiculares, retardando o início do processo de fixação biológica de nitrogênio.

A dupla inoculação BR3405 + Gigaspora margarita promoveu resposta mais lenta no crescimento da Sabiá, onde os melhores resultados para as plantas que receberam este tratamento foram constatados somente a partir dos 240 dias de cultivo, passando a apresentar médias estatisticamente semelhante às das plantas da inoculação conjunta.

A dupla inoculação BR3405 + Glomus clarum implicou em respostas mais rápida, favorecendo que as plantas deste tratamento apresentassem valores de médias de altura superiores aos das plantas inoculadas com BR3405 + Gigaspora margarita, até os sete meses de cultivo, constatando-se uma tendência, após esse período, de apresentar valores inferiores, porém, sem ser constatada diferença estatística.

A menor média de crescimento foi registrada para as plantas inoculadas com Glomus clarum + Gigaspora margarita. Esse fato sugere que os dois fungos juntos tenham funcionado apenas como um dreno de carboidratos do hospedeiro, e que devido à competição pelo estabelecimento da simbiose não forneceram ao mesmo tempo, nutrientes suficientes ao desenvolvimento da planta.

Segundo Caldeira et al. (2003), a espécie, o tipo de fungo micorrízico, o substrato, disponibi- lidade de nutrientes e $\mathrm{pH}$ do solo, são fatores que podem interferir na resposta da associação, podendo resultar em respostas positivas ou não da inoculação com os FMA.

\section{Crescimento em diâmetro do colo}

Para o crescimento em diâmetro do colo da Sabiá (Tabela 2), observou-se, ao longo do tempo, que as plantas que receberam a inoculação com o isolado Gigaspora margarita e as que receberam a inoculação conjunta com Glomus clarum + Gigaspora margarita + BR3405 responderam de maneira semelhante por todo o período de avaliação realizada no campo, ou seja, dos 120 aos 270 dias, apresentando, de modo geral, as melhores médias de crescimento, apesar de, na maioria das vezes, não ter sido detectada diferença estatística em relação a outros tratamentos.

Relacionando-se a altura com o diâmetro do colo das plantas inoculadas com o isolado Gigaspora margarita, observou-se que no período em que as plantas de Sabiá obtiveram as maiores médias para o diâmetro do colo, aos 210 e 240 dias (Tabela 2), registrou-se também, os melhores crescimentos em altura (Tabela 1), apesar de, estatisticamente, não terem diferido de outros tratamentos. Ainda, em termos da média de crescimento, as plantas inoculadas apenas com Gigaspora margarita apresentaram, ao término das análises do experimento, aos nove meses ( 270 dias) de cultivo, o segundo melhor crescimento, tanto para altura como para diâmetro do colo.

TABELA 2: Diâmetro do colo de mudas de Mimosa caesalpiniaefolia Benth., aos 120, 150, 180, 210, 240 e 270 dias inoculadas com fungos micorrízicos arbusculares e bactéria fixadora de nitrogênio, em campo no Instituto Agronômico de Pernambuco - IPA.

TABLE 2: Mimosa caesalpiniaefolia Benth. seedlings sward height at 30, 60, 90 days (greenhouse) 120, $150,180,210,240$ and 270 days (field) inoculated with arbuscular mycorrhizal fungi and nitrogen-fixing bacteria, at Instituto Agronômico de Pernambuco - IPA.

\begin{tabular}{|c|c|c|c|c|c|c|}
\hline \multirow{2}{*}{ Tratamentos } & \multicolumn{4}{|c|}{ Diâmetro do Colo (mm) } & \multirow[b]{2}{*}{240 dias } & \multirow[b]{2}{*}{270 dias } \\
\hline & 120 dias & 150 dias & 180 dias & 210 dias & & \\
\hline Testemunha Absoluta & $4,27 \mathrm{~b}$ & $4,94 \mathrm{ab}$ & 8,29 & $10,98 \mathrm{abc}$ & $12,36 \mathrm{ab}$ & $14,19 a b$ \\
\hline Gigaspora margarita & $4,63 \mathrm{ab}$ & $5,31 \mathrm{ab}$ & 7,90 & $12,15 \mathrm{a}$ & $13,83 \mathrm{a}$ & $16,02 \mathrm{a}$ \\
\hline Glomus clarum & $4,47 \mathrm{ab}$ & $5,00 \mathrm{ab}$ & 7,13 & $11,20 \mathrm{abc}$ & $12,68 \mathrm{ab}$ & $14,95 \mathrm{ab}$ \\
\hline BR3405 & $4,86 \mathrm{a}$ & $5,48 \mathrm{a}$ & 7,09 & $10,69 \mathrm{abc}$ & $12,22 \mathrm{ab}$ & $14,56 \mathrm{ab}$ \\
\hline BR3405 + Gigaspora margarita & $4,58 \mathrm{ab}$ & $5,20 \mathrm{ab}$ & 7,15 & $10,80 \mathrm{abc}$ & $12,52 \mathrm{ab}$ & $14,95 \mathrm{ab}$ \\
\hline BR3405+ Glomus clarum & $4,47 \mathrm{ab}$ & $5,13 a b$ & 6,87 & $10,347 b c$ & $12,45 \mathrm{ab}$ & $14,29 \mathrm{ab}$ \\
\hline Glomus clarum + Gigaspora margarita & $4,30 \mathrm{ab}$ & $4,81 \mathrm{~b}$ & 6,26 & $10,08 \mathrm{c}$ & $11,72 \mathrm{~b}$ & $13,47 \mathrm{~b}$ \\
\hline Glomus clarum + Gigaspora margarita + BR 3405 & $4,61 \mathrm{ab}$ & $5,40 \mathrm{a}$ & 7,55 & $11,91 \mathrm{ab}$ & $13,80 \mathrm{a}$ & $16,21 \mathrm{a}$ \\
\hline CV $(\%)$ & 17,84 & 15,66 & 43,76 & 20,10 & 19,55 & 19,17 \\
\hline
\end{tabular}

Em que: Médias seguidas de mesma letra não diferem estatisticamente entre si pelo teste de Tukey $(\mathrm{P}<0,05)$. 


\section{Estimativa de crescimento em altura e diâmetro do colo}

Na separação de médias de altura, pelo teste de Scott-Knott, constatou-se a formação de dois grupos. O grupo 1 foi composto pelos tratamentos Gigaspora margarita, BR3405 e Glomus clarum + Gigaspora margarita + BR3405; e o grupo 2 pelos tratamentos Testemunha Absoluta, Glomus clarum, Glomus clarum + Gigaspora margarita; BR3405 + Gigaspora margarita e BR3405 + Glomus clarum.

Para o diâmetro do colo na separação de médias, pelo mesmo teste de Scott-Knott, também se detectou a formação de dois grupos, sendo o grupo 1 composto pelos tratamentos Glomus clarum + Gigaspora margarita + BR3405 e Gigaspora margarita; e o grupo 2 foi composto pelos tratamentos Glomus clarum + Gigaspora margarita; Testemunha Absoluta, Glomus clarum, BR3405, BR3405 + Gigaspora margarita e BR3405 + Glomus clarum.

Desse modo, as equações de regressão obtidas pelo modelo de Chapman-Richards para estimativa de crescimento em altura e diâmetro do colo encontram-se na Tabela 3 e as curvas de crescimento, plotadas por grupos, encontram-se nas Figuras 1 e 2 .

As equações resultantes do modelo Chapman-Richards forneceram boas estimativas, permitindo explicar as variações de altura em $94 \%$ no Grupo I e 96 \% no Grupo II, e para o diâmetro em $94 \%$ nos Grupos 1 e 2. A análise dos gráficos apresenta boa adequação do modelo, demonstrando não tendenciosidade nos dados ajustados. Tonini et al. (2008), ao avaliarem o crescimento em altura e diâmetro de seis espécies nativas, obtiveram boas estimativas de crescimento por meio da função de Chapman-Richards. A grande flexibilidade que apresenta esse modelo permite o prognóstico do crescimento de árvores e povoamentos florestais em diferentes situações (ZEIDE, 1993; CAMPOS e LEITE, 2009).

\section{Conteúdos de $\mathbf{N}$ e P na parte aérea das plantas de Sabiá}

Para os conteúdos de Nitrogênio e Fósforo, na parte aérea das plantas de Sabiá, aos 150 e 240 dias após inoculação com fungos micorrízicos arbusculares e bactéria fixadora de nitrogênio, não se constatou diferença significativa entre os tratamentos testados. Apesar de os valores obtidos não terem diferenciado entre si pelo teste de Tukey $(\mathrm{P} \leq$ $0,05)$, ocorreu variação em relação aos conteúdos de nitrogênio e fósforo entre os diferentes tratamentos.

\section{Nitrogênio}

Constatou-se, aos 150 dias de cultivo, que as plantas de Sabiá inoculadas apenas com os isolados Gigaspora margarita e BR3405 foram as que apresentaram em sua parte aérea os maiores conteúdos de nitrogênio (Tabela 4).

TABELA 3: Equações de regressão, obtidas a partir do Modelo de Chapman-Richards, para estimativa de crescimento em altura e diâmetro do colo das mudas de Mimosa caesalpiniaefolia Benth. cultivadas sob diferentes tratamentos, em condições de campo, em Caruaru - PE.

TABLE 3: Regression equation, based on Chapman-Richards model, to growth and stem based diameter estimate of Mimosa caesalpiniaefolia Benth. seedlings, cultivated under different treatments, in the field conditions, in Caruaru, Pernambuco state..

\begin{tabular}{|c|c|c|c|c|c|}
\hline & & Altura & Diâmetro & & \\
\hline Grupo 1: & $\hat{\mathrm{H}}_{\mathrm{f}}=\mathrm{H}_{\mathrm{i}} *$ & $\begin{array}{c}1-\mathrm{e}^{-0,0353{ }^{*} t_{f}} \\
1-e^{-0,0353{ }^{*} t_{i}} \\
(\mathrm{IA}=0,94)\end{array}$ & $\hat{\mathrm{D}_{\mathrm{f}}}=\mathrm{D}_{\mathrm{i}} *$ & $\begin{array}{l}\frac{1-\mathrm{e}^{-0,0012 *_{\mathrm{f}}}}{1-\mathrm{e}^{-0,0012{ }_{\mathrm{t}}}{ }_{\mathrm{i}}} \\
(\mathrm{IA}=0,94)\end{array}$ & \\
\hline Grupo 2: & $\hat{\mathrm{H}_{\mathrm{f}}}=\mathrm{H}_{\mathrm{i}} *$ & 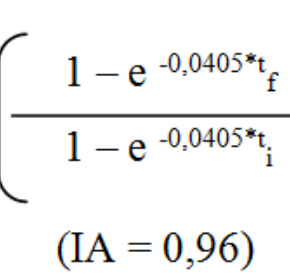 & $\hat{\mathrm{D}_{\mathrm{f}}}=\mathrm{D}_{\mathrm{i}} *$ & $\begin{array}{l}\frac{1-\mathrm{e}^{-0,0012 *_{\mathrm{f}}}}{1-\mathrm{e}^{-0,0012{ }_{\mathrm{t}}}{ }_{\mathrm{i}}} \\
(\mathrm{IA}=0,94)\end{array}$ & 1,2851 \\
\hline
\end{tabular}

Em que: $\mathrm{IA}=$ Índice de Ajuste (\%) 
GRUPO 1

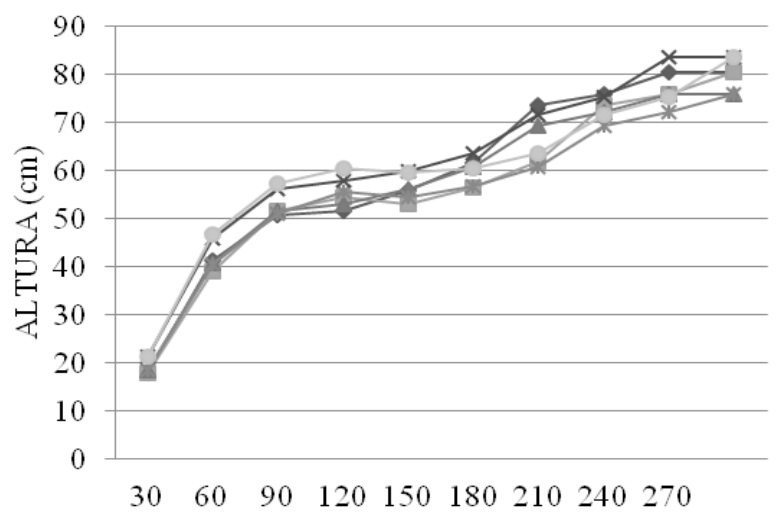

DIAS

GRUPO 2

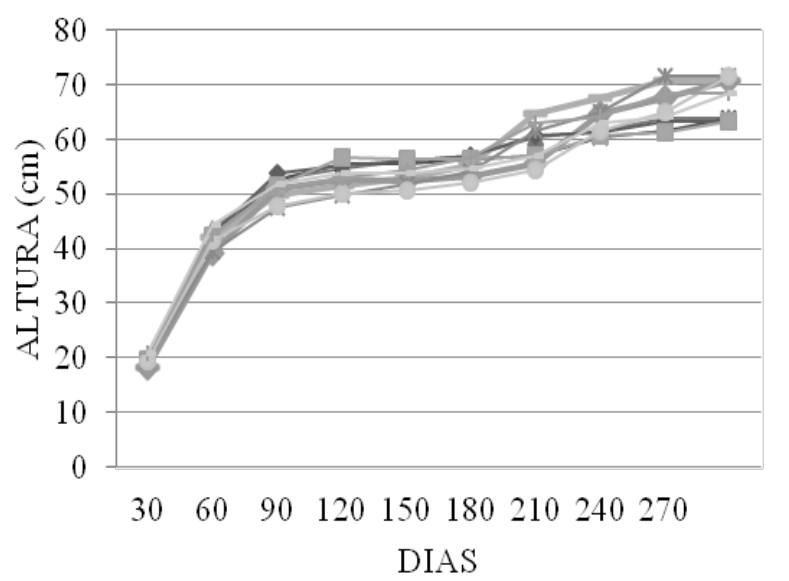

$\multimap$ GM (Real)

- - GM (Estimada)

$\longleftarrow$ BR3405 (Real)

- BR3405 (Estimada)

$\leftarrow$ GC+GM+BR3405 (Real)

$-\mathrm{GC}+\mathrm{GM}+\mathrm{BR} 3405$

(Estimada)

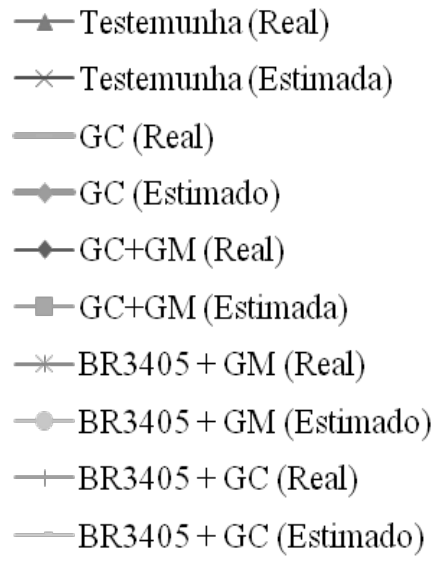

FIGURA 1: Curvas de crescimento em altura de mudas de Mimosa caesalpiniaefolia Benth., cultivadas sob os tratamentos Gigaspora margarita; BR3405; Glomus clarum + Gigaspora margarita + BR3405 (Grupo 1); Testemunha Absoluta; Glomus clarum; Glomus clarum + Gigaspora margarita; BR3405 + Gigaspora margarita; BR3405 + Glomus clarum (Grupo 2), observada (Real) e estimada pela equação, obtida do Modelo de Chapman-Richards.

FIGURE 1: Mimosa caesalpiniaefolia Benth. seedlings Height growth curve, cultivated under treatments Gigaspora margarita; BR3405; Glomus clarum + Gigaspora margarita + BR3405 (Group 1); Control Treatment; Glomus clarum; Glomus clarum + Gigaspora margarita; BR3405 + Gigaspora margarita; BR3405 + Glomus clarum (Group 2), observed (Real) and estimate for the equation, obtained from Chapman-Richards model.

Para esta época de avaliação, as plantas que não receberam inoculações (Testemunha Absoluta) apresentaram o menor conteúdo de nitrogênio, de modo que o conteúdo de nitrogênio nas plantas inoculadas com Gigaspora margarita foi $73,36 \%$ superior em relação ao conteúdo de $\mathrm{N}$ das plantas isentas de inoculação.

A melhor resposta observada da simbiose Gigaspora margarita x Sabiá, em relação ao conteúdo de $\mathrm{N}$, provavelmente se deve ao fornecimento de $\mathrm{P}$ às plantas, proporcionado pela simbiose, au- mentando sua capacidade de associação com rizóbios nativos do solo no local de cultivo, tendo em vista que o plantio foi realizado no solo natural, correspondente às reais condições de cultivo para os agricultores, com os micro-organismos nativos do solo interagindo com a planta e com os micro-organismos inoculados.

De acordo com Souza et al. (2007), uma leguminosa poderá se beneficiar da fixação biológica de nitrogênio, em dado local, se populações nativas de rizóbios compatíveis ocorrerem no solo. 

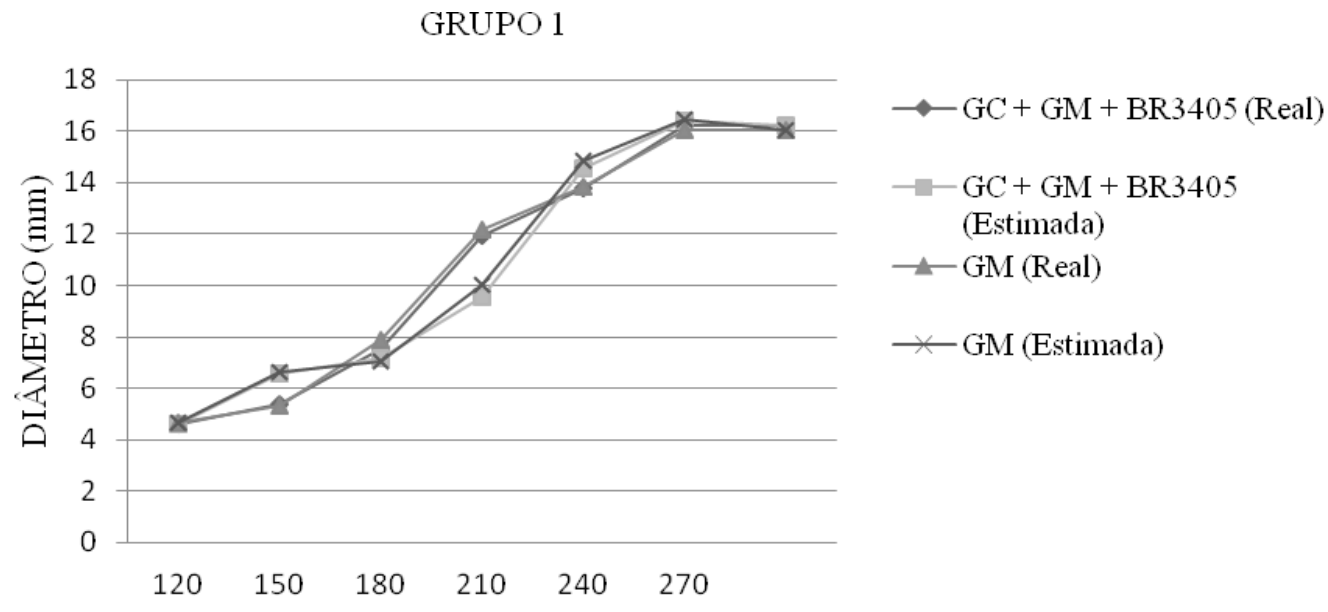

DIAS
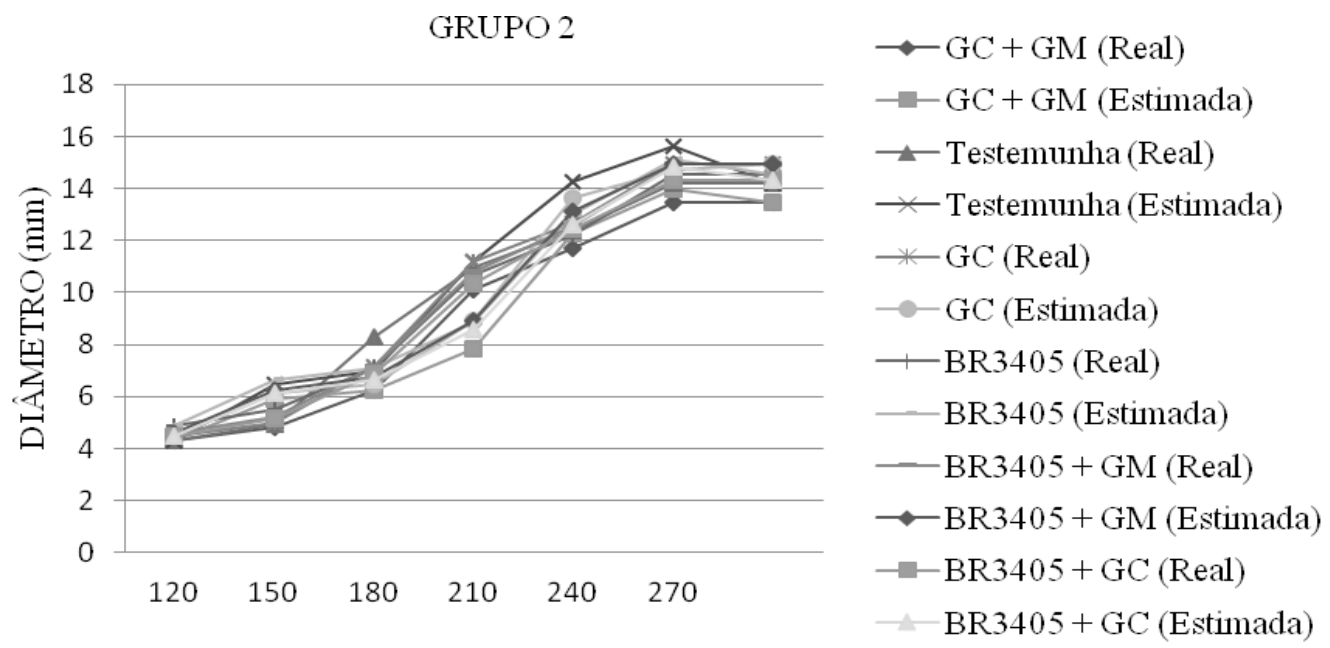

DIAS

FIGURA 2: Curvas de crescimento em diâmetro do colo de mudas de Mimosa caesalpiniaefolia Benth., cultivadas sob os tratamentos Glomus clarum + Gigaspora margarita + BR3405; Gigaspora margarita (Grupo 1); Glomus clarum + Gigaspora margarita; Testemunha Absoluta; Glomus clarum; BR3405; BR3405 + Gigaspora margarita; BR3405 + Glomus clarum (Grupo 2) observada (Real) e estimada pela equação, obtida do Modelo de Chapman-Richards.

FIGURE 2: Mimosa caesalpiniaefolia Benth. seedlings stem based diameter growth curve, cultivated under treatments Glomus clarum + Gigaspora margarita + BR3405; Gigaspora margarita (Group 1); Glomus clarum + Gigaspora margarita; Control Treatment; Glomus clarum; BR3405; BR3405 + Gigaspora margarita; BR3405 + Glomus clarum (Group 2), observed (Real) and estimate for the equation, obtained from Chapman-Richards model.

Para Chu et al. (2004), a presença de microbiota indígena, incluindo os fungos micorrízicos existentes, pode afetar o funcionamento da inoculação de espécies de FMA selecionadas. Assim, é importante estudar a resposta da inoculação no solo natural para prever o grau de sucesso da inoculação em condições de campo.

Na segunda avaliação, aos 240 dias, a inoculação com os isolados Gigaspora margarita e
BR3405 proporcionaram os melhores resultados em relação ao conteúdo de $\mathrm{N}$ na parte aérea das plantas de Sabiá, nas duas épocas de avaliação (150 e 240 dias). O menor conteúdo de nitrogênio na parte aérea das plantas de Sabiá foi obtido para as plantas que receberam a inoculação de Glomus clarum + Gigaspora margarita, sendo 70,61 \% inferiores as plantas inoculadas apenas com Gigaspora margarita. 
TABELA 4: Conteúdo total acumulado de nitrogênio e fósforo na parte aérea das mudas de Mimosa caesalpiniaefolia Benth., cultivadas no campo, em Caruaru - PE, aos 150 e 240 dias após inoculação com fungos micorrízicos arbusculares e bactéria fixadora de nitrogênio.

TABLE 4: Total content accumulated of nitrogen and phosphorus in Mimosa caesalpiniaefolia Benth. seedlings aerial parts, cultivated in the field, in Caruaru, Pernambuco state, at day 150 and 240 days after inoculation with arbuscular mycorrhizal fungi and nitrogen-fixing bacteria.

\begin{tabular}{lcccc}
\hline \multirow{2}{*}{ Tratamentos } & \multicolumn{2}{c}{$\begin{array}{c}\mathrm{N} \text { total acumulado } \\
\left(\mathrm{mg} \cdot \mathrm{g}^{-1}\right)\end{array}$} & \multicolumn{2}{c}{$\begin{array}{c}\text { P total acumulado } \\
\left(\mathrm{mg} \cdot \mathrm{g}^{-1}\right)\end{array}$} \\
\cline { 2 - 5 } & 150 dias & 240 dias & 150 dias & 240 dias \\
\hline Testemunha Absoluta & 31,705 & 123,682 & 0,733 & 3,946 \\
Gigaspora margarita & 54,964 & 162,930 & 1,447 & 6,608 \\
Glomus clarum & 40,483 & 117,836 & 1,328 & 6,177 \\
BR3405 & 54,378 & 150,181 & 1,839 & 5,784 \\
BR3405 + Gigaspora margarita & 38,726 & 112,411 & 1,109 & 4,635 \\
BR3405 + Glomus clarum & 42,583 & 128,804 & 0,962 & 2,528 \\
Glomus clarum + Gigaspora margarita & 38,425 & 95,496 & 1,626 & 1,343 \\
Glomus clarum + Gigaspora margarita + BR3405 & 37,367 & 140,603 & 1,593 & 5,669 \\
\hline
\end{tabular}

\section{Fósforo}

$\mathrm{O}$ maior conteúdo de $\mathrm{P}$ foi registrado aos 150 dias nas plantas de Sabiá que receberam a inoculação isolada de BR3405, tendo sido 150,91\% superiores às plantas isentas de inoculações, que por sua vez apresentaram o menor conteúdo desse nutriente (Tabela 4).

Aos 240 dias de cultivo, a inoculação com o isolado Gigaspora margarita foi o tratamento que proporcionou os maiores valores de conteúdo de fósforo na parte aérea das plantas de Sabiá. Observou-se, ainda, que a inoculação com Glomus clarum + Gigaspora margarita foi o tratamento que proporcionou o menor conteúdo de fósforo na parte aérea, e as plantas inoculadas apenas com Gigaspora margarita apresentaram conteúdo $391,85 \%$ superior às inoculadas com Glomus clarum + Gigaspora margarita. Tal fato pode explicar o que ocorreu para os parâmetros altura (Tabela 1) e diâmetro do colo (Tabela 2), que para esta época de avaliação (240 dias), a inoculação com os dois fungos (Glomus clarum + Gigaspora margarita) foi também o tratamento que apresentou a menor média de crescimento, sendo inferido, portanto, como o tratamento que proporcionou os menores valores para todas as variáveis avaliadas (altura, diâmetro do colo, conteúdos de nitrogênio e fósforo) às plantas de Sabiá. Esse fato comprova a hipótese de que os dois fungos juntos tenham funcionado como um dreno de carboidratos do hospedeiro, e que devido à competição pelo estabelecimento da simbiose não conseguem fornecer ao mesmo tempo, nutrientes suficientes ao desenvolvimento da planta.

Assim, pelos resultados obtidos no presente estudo com a inoculação concomitante de dois FMA (Glomus clarum + Gigaspora margarita), reforça-se a importância de que mais estudos sejam realizados para investigar as relações de intraespecificidade entre FMA, bem como possíveis graus de especificidade e/ou afinidade dos FMA com seu hospedeiro. Pois, segundo Miranda et al. (2008), é sabido que as plantas podem se beneficiar de forma diferenciada das diversas combinações entre espécies de fungos e planta hospedeira, e que o conhecimento da interação entre as plantas cultivadas e os diferentes fungos micorrízicos é importante para o progresso de sistemas de manejo mais sustentáveis.

\section{Sobrevivência de plantas de Sabiá}

Decorridos 270 dias (9 meses) de cultivo da Sabiá, sendo 90 dias em casa de vegetação, mais 180 dias em campo, não foi detectada mortalidade das plantas cultivadas sob os diferentes tratamentos, obtendo-se, portanto, uma sobrevivência de $100 \%$, independente do tratamento utilizado. Isso corrobora com a afirmação de Souchie et al. (2005), que a inoculação de micro-organismos benéficos, como os fungos micorrízicos arbusculares e bactérias fixadoras de nitrogênio, pode beneficiar o desenvolvimento das mudas em viveiro, maximizando assim a capacidade de estabelecimento das mudas em campo. 
Agregado a este fato, tem-se a própria característica ecológica da Sabiá. A rusticidade inerente à espécie contribui para maior resistência aos estresses de transplante e plantio no campo, com respostas diretas sob a sua sobrevivência em campo. Silva (2000) observou sobrevivência mínima de $70 \%$ na espécie quando estudou a mesma em um solo em processo de erosão, simulada pela gradual remoção de lâminas do perfil e decréscimo nos teores de matéria orgânica, em incrementos de $5 \mathrm{~cm}$ a partir da superfície do solo, compondo camadas até 25$40 \mathrm{~cm}$. Gama-Rodrigues et al. (2008) trabalharam com a Sabiá (Mimosa caesalpiniaefolia) e Acácia (Acacia auriculiformis), inoculadas com estirpes selecionadas de bactérias fixadoras de $\mathrm{N}_{2}$ atmosférico e fungos micorrízicos arbusculares, combinado de Gigaspora margarita e Glomus clarum. Estes autores avaliaram a sobrevivência das plantas 15 meses após o plantio e observaram que a Sabiá apresentou a maior taxa de sobrevivência, com $87 \%$, e a acácia com $74 \%$ de sobrevivência.

De um modo geral, a sobrevivência de mudas após a sua implantação é um fator que pode estar relacionado com alguns procedimentos durante a sua fase de produção. Dessa forma, espera-se que mudas produzidas com melhores condições morfofisiológicas, advindas dos benefícios que as bactérias fixadoras de nitrogênio e fungos micorrízicos arbusculares proporcionam, possuam melhores taxas de sobrevivência.

Resultados semelhantes ao presente estudo foram obtidos por Mendonça et al. (2008), ao trabalharem com mudas de Sabiá inoculadas com estirpe de rizóbio específico. As plantas, produzidas em casa de vegetação por um período de três meses, foram plantadas em uma área degradada pela extração de argila no município de Campos dos Goytacazes - RJ, sem que houvesse nenhuma adubação de plantio. Estes autores obtiveram uma alta sobrevivência da espécie em todos os tratamentos avaliados, onde a menor taxa obtida foi de $95,8 \%$, variando até $100 \%$.

A predominância de resultados de taxas de sobrevivência satisfatórias para a Sabiá sugere a alta adaptabilidade que a espécie pode apresentar para sua utilização em programas de restauração de áreas degradadas, com consequente redução de custos de replantio de mudas mortas.

\section{CONCLUSÕES}

A inoculação conjunta de Glomus clarum
+ Gigaspora margarita + BR3405, assim como a inoculação com o isolado Gigaspora margarita proporcionaram melhores condições de crescimento para a Sabiá.

O modelo de Chapman-Richards mostrou-se adequado para descrever o crescimento em altura e diâmetro das plantas de Sabiá.

Os micro-organismos inoculados favoreceram os conteúdos de N e P nas plantas de Sabiá, inferindo redução no uso de fertilizantes.

A espécie Sabiá apresentou $100 \%$ de sobrevivência, independente da inoculação com micro-organismos simbiontes.

\section{REFERÊNCIAS BIBLIOGRÁFICAS}

ANDRADE, D. de S.; HAMAKAWA, P. J. Estimativa do número de células viáveis de rizóbio em solo e em inoculantes por infecção em plantas. In: HUNGRIA, M.; ARAÚJO, R.S. (Eds.) Manual de métodos empregados em estudos de microbiologia agrícola. Brasília: Serviço de Produção de Informação, 1994. Cap.3, p. 63-94. (Embrapa-CNPAF. Documentos, 46).

ARAÚJO FILHO, J. A. de. et al. Avaliação de leguminosas arbóreas, para recuperação de solos e repovoamento em áreas degradadas, QuixeramobimCE. Revista Brasileira de Agroecologia, v. 2, n. 2, p.1592-1595, 2007.

BRAGA, R. Plantas do Nordeste, especialmente do Ceará. 3. ed. Mossoró: ESAM 1976, 540 p.

CALDEIRA, M. V. W. et al. Influência de fungos micorrízicos arbusculares sobre o crescimento de três leguminosas arbóreas. Revista Acadêmica: ciências agrárias e ambientais, Curitiba, v.1, n.1, p. 27-32, 2003.

CAMPOS, J. C. C.; LEITE, H. G. Mensuração florestal: perguntas e respostas. 3. ed. Viçosa: Universidade Federal de Viçosa, 2009. 548 p.

CHU, E. Y.; YARED, J. A. G.; MAKI, H. J. I. O. Efeitos da inoculação micorrízica e da adubação fosfatada em mudas de Vochysia maxima Ducke. Revista Árvore, v. 28, n. 2, p. 157-165, 2004. COLOZZI-FILHO, A.; NOGUEIRA, M. A. Micorrizas Arbusculares em Plantas Tropicais: Café, Mandioca e Cana-de-açúcar. In: SILVEIRA, A. P. D. da.; FREITAS, S. dos. S. Microbiota do solo e qualidade ambiental. Campinas: Instituto Agronômico, 2007. $312 \mathrm{p}$.

FIGUEIRÔA, J. M. de. et al. Madeireiras. In: SAMPAIO, E. V. S. B. et al. (Eds.). Espécies da flora nordestina de importância econômica potencial. 
Recife: Associação Plantas do Nordeste, 2005. p. 101-133.

FRANCO, A. A. et al. Uso de leguminosas florestais noduladas e micorrizadas como agentes de recuperação e manutenção da vida do solo: um modelo tecnológico. In: ESTEVES, F. A. (Ed.) Estrutura, funcionamento e manejo de ecossistemas brasileiros. Oecologia Brasiliensis, Rio de Janeiro: UFRJ, v. 1, 1995, p. 459-467.

GAMA-RODRIGUES, E. F. da. et al. Atributos químicos e microbianos de solos sob diferentes coberturas vegetais no norte do estado do Rio de Janeiro. Revista Brasileira de Ciência do Solo, v. 32, p. 1521-1530, 2008.

GERDEMANN, J. W.; NICOLSON, T. H. Spores of mycorrhizal Endogone species extracted from soil by wet sieving and decanting. Transactions of the British Mycological Society,v. 46, p. 235-244, 1963.

JENKINS, W. R. A rapid centrifugal-flotation technique for separating nematodes from soil. Plant Disease Report, v. 48, p. 692, 1964.

JESUS, E. da. C.; SCHIAVO, J. A.; FARIA, S. M. de. Dependência de micorrizas para a nodulação de leguminosas arbóreas tropicais. Revista Árvore, v. 29, n. 4, p. 545-552, 2005.

LASTE, K. C. D.; GONÇALVES, F. S.; FARIA, S. M. de. Estirpes de rizóbio eficientes na fixação biológica de nitrogênio para leguminosas com potencial de uso na recuperação de áreas mineradas. Seropédica: Embrapa, 2008. 8 p. (Embrapa. Comunicado Técnico, 115).

LIMA, I. C. A. R. de. et al. Avaliação de sabiazeiro (Mimosa caesalpiniaefolia Benth.) quanto a acúleos e preferência por bovinos. Revista Brasileira de Ciências Agrárias, v. 3, n. 3, p. 289-294, 2008.

LORENZI, H. Árvores brasileiras: manual de identificação e cultivo de plantas arbóreas nativas do Brasil. 4. ed. Nova Odessa: Plantarum, 2002. 368p. v. 1.

MENDONÇA, A. V. R. et al. Atributos edáficos de cavas de extração de argila após cultivos puros e consorciados de Eucalyptus spp. e Mimosa caesalpiniifolia BENTH. (Sabiá) e quantificação da poda de Sabiá. Floresta, v. 38, n. 3, p. 431-443, 2008.

MIRANDA, E. M. de.; SAGGIN JÚNIOR, O. J.; SILVA, E. M. R. da. Seleção de fungos micorrízicos arbusculares para o amendoim forrageiro consorciado com braquiária. Pesquisa Agropecuária Brasileira, v. 43, n. 9, p. 1185-1191, 2008.

NOBRE, A. P. Respostas de mudas de Gliricidia sepium à aplicação de nitrogênio e fósforo. 2008. 56 f. Dissertação (Mestrado em Zootecnia) Universidade Federal de Campina Grande, Patos PB.

PEIXOTO, R. S.; ROSADO, A. S. Monitoramento de impactos sobre a diversidade microbiana em solos agrícolas. In: FIGUEIREDO, M.V.B. et al. Micro-organismos e agrobiodiversidade: 0 novo desafio para agricultura. Guaíba: Agrolivros. 2008. p.507-526.

RIBASKI, J. et al. Sabiá (Mimosa caesalpiniaefolia) árvore de múltiplo uso no Brasil. Colombo: Embrapa Florestas, 2003. 4 p. (Embrapa Florestas. Comunicado Técnico, 104).

RIZZINI, C. T. Plantas do Brasil árvores e madeiras úteis do Brasil: manual de dendrologia brasileira. 2. ed. São Paulo: E. Blücher, 1978. 296 p. RODRIGUES, L. A. et al. Revegetação de áreas degradadas pela extração de argila no Norte do Estado do Rio de Janeiro. Perspectivas, v. 5, n. 10, p. 88-105, 2006.

SANTOS, C. E. de. R. e. S. et al. Fixação simbiótica do $\mathrm{N}_{2}$ em leguminosas tropicais. In: FIGUEIREDO, M.V.B. et al. Micro-organismos e agrobiodiversidade: o novo desafio para agricultura. Guaíba: Agrolivros. 2008. p.17-41.

SILVA, J. R. C. Sobrevivência e crescimento de mudas de Sabiá em podzólico vermelho-amarelo sob erosão simulada. Pesquisa Agropecuária Brasileira, Brasília, v. 35, n. 5, p. 1055-1061, 2000. SILVA, M. B. R. et al. Estresse salino em plantas da espécie florestal sabiá. Caminhos de Geografia, v. 10, n. 30, p. 120-127, 2009.

SOUCHIE, E. L. et al. Mudas de espécies arbóreas inoculadas com bactérias solubilizadoras de fosfato e fungos micorrízicos arbusculares. Floresta, v. 35, n. 2, p. 329-334, 2005.

SOUZA, F. A. de.; SILVA, E. M. R. da. Micorrizas arbusculares na revegetação de áreas degradadas. In: SIQUEIRA, J. O. (Ed.). Avanços em fundamentos e aplicação de micorrizas. Lavras: Universidade Federal de Lavras, 1996. p. 255-290.

SOUZA, L. A. G. de. et al. Desenvolvimento e nodulação natural de leguminosas arbóreas em solos de Pernambuco. Pesquisa Agropecuária Brasileira, v. 42, n. 2, p. 207-217, 2007.

STÜRMER, S. L. et al. "Além das raízes": o papel dos fungos micorrízicos. Boletim Informativo da SBCS, p. 30-32, jan.-abr. 2009.

TOLEDO, B. F. B. de.; MARCONDES, J.; LEMOS, E. G. de. M. Caracterização de rizóbios indicados para produção de inoculantes por meio 
de sequenciamento parcial do $16 S r R N A$. Pesquisa Agropecuária Brasileira, v. 44, n. 4, p. 384-391, 2009.

TONINI, H.; OLIVEIRA JÚNIOR, M. M. C. de.; SCHWENGBER, D. Crescimento de espécies nativas da Amazônia submetidas ao plantio no Estado de Roraima. Ciência Florestal, Santa Maria, v. 18, n. 2, p. 151-158, abr./jun. 2008.

VINCENT, J.M. A manual for the practical study of the root-nodule bacteria. London: International Biological Programme, 1970. 164 p. (IBP. Handbook, 15).

ZEIDE, B. Analysis of growth equations. Forest Science, v. 39, n. 3, p. 594-616, 1993. 